\title{
A PERCEPÇÃO DAS ENFERMEIRAS SOBRE A COMPETÊNCIA SOCIAL NO DESENVOLVIMENTO DA ASSISTÊNCIA PRÉ-NATAL
}

\author{
Nurses' perception of social competence when delivering \\ Pre-natal assistance \\ La percepción de las enfermeras sobre la competencia social en \\ el desarrollo de la asistencia prenatal
}

Yara Macambira Santana Lima

Maria Aparecida Vasconcelos Moura²

\section{RESUMO}

Trata-se de um recorte da tese em construção; tem como objetivo analisar a competência social das enfermeiras na assistência pré-natal. Participaram 42 enfermeiras que realizam assistência à gestante no contexto da Política Nacional de Atenção Integral à Saúde da Mulher desenvolvida nas Unidades Municipais de Saúde de Belém-Pará. Pesquisa qualitativa, referencial teórico da qualidade de Claus Moller (1992), descreve o lado humano da qualidade pessoal. Os dados foram coletados em formulários preenchidos com assistência direta da pesquisadora; as questões éticas obedeceram à Resolução n 196/96, do CNS. Na análise dos resultados, emergiu a categoria temática da competência social, que na percepção das depoentes reflete o compromisso profissional diante das gestantes, compreende a necessidade da busca de uma consciência crítica da realidade e o interesse em superar as dificuldades nos serviços de saúde pública. Não é suficiente somente ter um bom desempenho profissional, é fundamental o apoio institucional para promover o crescimento pessoal.

Palavras-chave: Enfermeiras. Cuidado Pré-Natal. Gestão de Qualidade.

\begin{abstract}
This study, an extract from a dissertation in progress, aims to analyze a social competence of the nurses when delivering prenatal assistance. Forty-two nurses, engaged in the Politics National Women's Health Care, carried out at the Municipal Health Care Centers in Belem, Pará, have taken part in the project. This is a qualitative research based on Claus Moller's quality standards (1992) which describes the human aspect of personal quality. Data has been collected through questionnaires completed under the researcher's supervision. The ethical issues raised were in compliance with the National Health Board Resolution number 196/96. As a result of the data analysis, the category of social competence emerged. According to the subjects interviewed, it comprises the nurses' professional commitment to the pregnant women they assist; their need to have a more critical attitude towards reality and their willingness to overcome the difficulties inherent in the public health services. This reseach shows that not only good professional performance, but also institutional support are essential to ensure personal development.
\end{abstract}

Keywords: Nurses. Pre-Natal Care. Quality Management

\section{Resumen}

Este trabajo es un recorte de la tesis en construcción y tiene como objetivo analizar la competencia social de la enfermera en la asistencia prenatal. Participaron 42 enfermeras que realizan asistencia a la gestante en el contexto de la Política Nacional de Atención Integral a la Salud de la Mujer, ocurrida en las Unidades Municipales de Salud de Belém/Pará.. Investigación cualitativa, referencial teórico de la cualidad de Claus Moller (1992), que describe el lado humano de la calidad personal. Los datos fueron colectados en formularios rellenados con la asistencia directa de la investigadora y las cuestiones éticas obedecieron a la Resolución n 196/96, del CNS. En la análisis de los resultados emergió la categoría temática de la competencia social, que, en la percepción de las deponentes, refleja el compromiso profesional delante de las gestantes, comprendiendo la necesidad de la busca de una consciencia crítica de la realidad y el interés de superar las dificultades en los servicios de salud pública. No es suficiente solamente tener un bueno desempeño profesional, es fundamental el apoyo institucional para promover el crecimiento personal.

Palabras-claves: Enfermeras. Atención Prenatal. Gestión de Cualidad.

\footnotetext{
${ }^{1}$ Doutoranda em Enfermagem da EEAN/UFRJ; Professora Assistente III da Universidade do Estado do Pará, Membro do NUPESM da EEAN/UFRJ. Email: yaramac@amazon.com.br ${ }^{2}$ Doutora em Enfermagem.Professora Associada I do Departamento de Enfermagem Materno-Infantil da EEAN/UFRJ; Membro da Diretoria Colegiada do NUPESM da EEAN/UFRJ. Email: maparecidavas@yahoo.com.br
} 


\section{INTRODUCÃO}

Este artigo é um recorte dos resultados de pesquisa da tese de doutorado desenvolvida na Escola de Enfermagem Anna Nery/UFRJ (2008). Apresenta como objeto o desempenho das enfermeiras na assistência pré-natal. No contexto da construção da percepção das enfermeiras sobre a competência social, o desenvolvimento da força de trabalho em saúde pública consiste em uma abordagem integrada e complexa, que envolve os serviços de saúde, mercado de trabalho, sindicatos, organizações profissionais e as instituições formadoras. ${ }^{(1,2)}$

A idéia de competência social no lugar de qualificação técnica toma força à medida que requisitos como a responsabilidade, abstração e a interdependência entram no registro do trabalho e evocam os chamados "saber social" ou "saber-ser". Para Deluiz ${ }^{3}$, a competência traduz-se no saberser. No entanto, observa que a noção de saber social pode sugerir que nem todos os saberes sociais são sociais, gerando uma apreensão exógena da técnica.

Nesse sentido, competência tem significados distintos, tanto ligados às atividades e aos resultados, como às características das pessoas. Desta forma, a troca de competências ocorre quando existe uma interação das pessoas com o ambiente organizacional. Sendo assim, tem sido definida como um saber agir responsável e reconhecido que implica mobilizar, integrar, transferir conhecimentos, recursos, habilidades, que agreguem valor econômico à organização e valor social ao indivíduo. ${ }^{(4,5)}$

Quanto à enfermeira na assistência pré-natal, esta tem um papel fundamental no desenvolvimento das atividades de atenção básica à saúde da mulher. Porém, temos que considerar que a repetição e a rigidez das atividades levam à alienação da enfermeira que não se dá conta da importância de sua atividade para conseguir equidade e qualidade na prestação dos serviços, com eficácia e eficiência para a satisfação do usuário ${ }^{6}$.

Apesar disso, as enfermeiras no desenvolvimento de suas atividades junto às gestantes têm a percepção de que devem desenvolver as suas funções com competência, conhecimento e compromisso profissional, independente das condições de estrutura física ou de recursos humanos e/ou matérias. No entanto, Moller ${ }^{7}$ afirma que o desempenho profissional abrange a satisfação das exigências técnicas e humanas necessárias ao desenvolvimento de um trabalho com excelência. Com este pensamento, procuramos aprofundar esta pesquisa com 0 objetivo de descrever e analisar a competência social das enfermeiras na assistência pré-natal.

\section{METODOLOGIA}

0 estudo tem como proposta metodológica uma pesquisa de abordagem qualitativa sustentada no referencial teórico da qualidade pessoal de Claus Moller, o qual valoriza o lado humano da qualidade profissional. 0 enfoque pode ser considerado apropriado, uma vez que o objeto do estudo encaminha-se para definir a proposta no contexto dos pressupostos da pesquisa social. Nesse campo de investigação, os princípios de especificidade histórica e de totalidade conferem potencialidade para apreender e analisar os acontecimentos, relações e os critérios de complexidade e de diferenciação de um determinado fenômeno ${ }^{8}$.

Apesar de o objeto contemplar o desempenho das enfermeiras na assistência pré-natal, nos relatos das enfermeiras emergiram unidades de análises que favoreceram a identificação da percepção das enfermeiras sobre a competência social no desenvolvimento da assistência pré-natal, considerando que estas profissionais servem como ponto de referência no sentido de descrever a sua atuação e 0 compromisso profissional, o que é considerado por Chiavenato ${ }^{9}$ uma das dimensões da competência profissional.

Os atores sociais foram quarenta e duas (42) enfermeiras que desenvolvem suas atividades na assistência de enfermagem pré-natal no Programa de Atenção à Saúde da Mulher, nas Unidades Municipais de Saúde de Belém, cenário desta pesquisa. 0 critério para inclusão delas foi que estivessem trabalhando no mínimo há um ano na rede ambulatorial do município e que desejassem participar voluntariamente da pesquisa, assinando o termo de consentimento livre e esclarecido. Este foi elaborado de acordo com a Resolução n $196 / 96$, do Conselho Nacional de Saúde (CNS) e aprovado no CEP/Campus IV/CCBS/UEPa em 23.02.2008. Para identificação dos sujeitos, foram utilizados os pseudônimos de pedras preciosas, como forma de garantir o sigilo e 0 anonimato das depoentes.

A coleta de dados foi realizada no primeiro semestre de 2007. Para obter as informações, utilizamos um formulário com 10 questões abertas, que foi respondido durante o contato com as enfermeiras nas Unidades Municipais de Saúde, ocasião que possibilitou uma aproximação com os atores sociais, esclarecendo dúvidas ou colocando-nos a disposição pra complementar algum questionamento.

Considerando o desempenho pessoal na questão da pesquisa, optamos pela escolha de aplicação de formulário, a fim de permitir que as enfermeiras tivessem liberdade de expressar na escrita seus pensamentos, sem o constrangimento que porventura pudesse ocorrer se realizássemos 0 questionamento verbal.

Para análise e interpretação das informaç̃̃es obtidas, optamos por uma adequação da técnica de análise de conteúdo, a análise temática, definida como um conjunto de técnicas de análise das comunicações, que utiliza procedimentos sistemáticos e objetivos de descrição dos conteúdos das mensagens ${ }^{10}$. Nesse processo, foram identificadas as unidades de registro e nomeados os temas, e esses foram agrupados em conjuntos maiores por afinidade de significação. Através desse movimento de organizar os resultados de análise, identificamos as categorias. 


\section{A Enfermeira na Assistência Pré-Natal}

Na evolução histórica da assistência de enfermagem, um dos marcos mais relevantes se traduz pela Lei $n^{0} 7.498 / 86$ do Exercício Profissional, que estabelece a consulta de enfermagem entre as competências da enfermeira. Porém, no início da profissão, era considerada auxiliar, subsidiária do trabalho, a enfermeira que exercia atividades predominantes na área de Saúde Pública e, nesse contexto, realizava atendimento individual no programa pré-natal. A atuação desta estava relacionada à coleta de informações preliminares (préconsulta) e posterior encaminhamento para serviços especializados ou pós-consulta.

Assim, a inserção das enfermeiras no desempenho da assistência pré-natal foi instituída no país, em decorrência de um processo que tem suas raízes nos primórdios da profissão, sendo atualmente considerada uma atividade institucionalizada, tanto na área do ensino como nos serviços prestados pelas esferas municipal, estadual e federal.

Embora posicionada em igualdade de condições com os demais profissionais, as enfermeiras continuam sentindo a repercussão do atrelamento da enfermagem à medicina ${ }^{11}$. Ainda existe o reflexo da dominação do poder e saber médico na prática de saúde, com a conseqüente subordinação da enfermagem. Ainda persiste o modelo biomédico, extremamente funcionalista, neoliberal e tecnicista, que fortifica uma posição de poder e hegemonia médica entre as categorias de profissionais.

A enfermeira encontra-se integrada à equipe de saúde responsável por essa assistência, realizando atividades que devem ser organizadas para atender às reais necessidades da população feminina, utilizando conhecimentos técnicocientíficos e os recursos disponíveis de acordo com a realidade local, e na construção de seu desempenho na assistência prénatal.

Com este pensamento, Martins ${ }^{11}$ afirma que a consulta de pré-natal de baixo risco, realizada por enfermeiras, deve ser desenvolvida voltada para uma prática multidisciplinar institucional e social, objetivando mudanças de concepções assistenciais com formas de abordagens integrais como preconiza a atenção à saúde da mulher, ultrapassando, assim, os modelos tradicionais de saúde.

0 movimento das mulheres representou papel fundamental para os avanços ocorridos com a implantação da Política Nacional de Atenção Integral à Saúde da Mulher ${ }^{12}$, que contempla os princípios preconizados pela Constituição Brasileira (1988) e pelo Sistema Único de Saúde (SUS), os quais fundamentam suas ações básicas nas diretrizes programáticas.

Entretanto, ainda hoje é um grande desafio para os profissionais de saúde, e principalmente para as enfermeiras, como categoria predominantemente feminina, incluir na assistência materna fatores psicossociais relacionados com os direitos da mulher na sociedade e no contexto familiar, possibilitando que a gestante realmente seja vista no papel de sujeito da cidadania.

Este desafio deve ultrapassar o modelo biomédico e acima de tudo romper com o paradigma da assistência à mulher como objeto da reprodução. Para isso é de fundamental importância a formação acadêmica, construindo um novo olhar para assistir a essa mulher-cidadã. Contrapondo este modelo, deparamos com o fato de que, na rede municipal de saúde, a assistência pré-natal desenvolvida por enfermeiras ainda é direcionada somente para os problemas de natureza obstétrica e ginecológica, persistem as ações para o sujeito de reprodução.

\section{RESULTADOS E DISCUSSÃO}

\section{Caracterização das Enfermeiras das Unidades Municipais de Saúde em Belém:}

0 tempo de atuação das enfermeiras na assistência prénatal variou de 1 a 28 anos, com predominância do período entre 5 e 10 anos (21 participantes), seguido de 1 a 4 anos (10 participantes). A maioria realizou curso de graduação no próprio estado, entre a Universidade Federal do Pará e a do Estado do Pará; somente três são graduadas em outro estado, sendo duas no Ceará e uma no Rio de Janeiro. Verificamos maior concentração de graduadas no Estado do Pará.

Quanto às depoentes, verificamos que quase a totalidade não teve oportunidade de escolha para trabalhar na assistência pré-natal por ocasião da admissão, e apenas 22 enfermeiras realizaram curso de atualização na assistência pré-natal, nos dois últimos anos. Importante notar que uma característica dessas profissionais da região é o fato de terem mais de um vínculo empregatício, e algumas dispõem de até três empregos, inclusive, em um deles, desenvolvendo atividades em serviço noturno.

A situação apresentada é fruto da questão salarial, pois a realidade regional demonstra que, tanto na assistência como na docência, os rendimentos salariais dos profissionais de saúde na região norte, e, no caso em pesquisa, no município de Belém, apresentam uma defasagem aquém das demais regiões; isso de certa forma contribui para que as enfermeiras necessitem atuar em diversas áreas. Uma pesquisa realizada pelo Conselho Regional de Enfermagem do Pará (COREN-PA) constatou que o salário dos professores da Universidade do Estado do Pará está abaixo da média de todo o país.

Apesar de a maioria atuar na área de assistência materna há mais de 10 anos, das 42 depoentes que fizeram parte da pesquisa, somente cinco realizaram o Curso de Especialização em Enfermagem Obstétrica. Por conta da diversificada atuação, podemos observar as diferentes áreas de realização de Cursos de Especialização, além da Enfermagem Obstétrica (05), identificamos também: Administração Hospitalar (06), Saúde Pública (08), Saúde do Trabalhador (05), Saúde Coletiva (04), Docência em Ensino Superior (02), Saúde da Família (01), Saúde do Idoso (01), Enfermagem em CTI (01), Resíduos em 
Serviço de Saúde (01) e Enfermagem em Doenças Tropicais (01).

Os dados reforçam a atuação das enfermeiras em diversas áreas; apesar de todas as depoentes atuarem na assistência pré-natal, a maioria apresenta especialização nas áreas de Administração e Saúde Pública. Tal fato aponta para a necessidade de investimento pessoal e institucional no sentido de realização de qualificação profissional de enfermeiras na área obstétrica, uma vez que somente cinco depoentes apresentam especialização em Enfermagem Obstétrica.

Para o alcance dos objetivos, após a obtenção dos resultados de análise dos formulários, foram construídas as unidades de significação, que serviram de base para identificação e construção das seguintes categorias: a competência social e o compromisso profissional e social das enfermeiras na assistência pré-natal.

\section{Categoria 1- A COMPETÊNCIA SOCIAL NA PERCEPÇÃO DAS ENFERMEIRAS NA ASSISTÊNCIA PRÉ-NATAL}

Consideramos que a competência individual é o processo pelo qual o profissional deve mobilizar seus conhecimentos e habilidades para produzir qualidade. Trata-se de uma resposta prática adaptada a uma situação específica; portanto, a competência é a capacidade em ação, ou seja, a mobilização da potencialidade deste profissional apropriado para solução de determinado problema, cuja ação reflete na assistência prénatal.

Numa instituição de serviços de saúde, a competência profissional deveria ser avaliada na prática. Entretanto, por mais universal que seja, a competência depende de um contexto em que cada indivíduo carrega consigo, ou seja, seus conhecimentos e habilidades. Com isso, quanto maior a competência, maiores serão as chances dos profissionais em realizar suas atividades e alcançar o desempenho ideal.

Embora existam diversos fatores que contribuam e influenciam no desempenho das Enfermeiras, na assistência pré-natal, evidenciamos relatos em que as condições de trabalho são extremamente variáveis e determinantes para a maioria delas, assim como a necessidade de desenvolver um sistema de avaliação profissional no sentido de aproximar a prática dos objetivos propostos pela instituição.

Do ponto de vista das depoentes, torna-se necessário criar uma metodologia que programe na prática o investimento contínuo e sistematizado do desempenho dessas enfermeiras na assistência pré-natal, compondo-se de forma integral com os demais processos gerenciais. Esta situação vem sendo observada nas instituições bem-sucedidas, em que os profissionais são tratados como parceiros do negócio e fornecedores de competências 9 .

Neste sentido, a instituição, por meio da ação gerencial no dia-a-dia de trabalho, precisa assegurar que o desempenho produza o resultado esperado, atuando ativamente no sentido de identificar os desvios do desempenho e agir sobre as causas que provocaram esses desvios ${ }^{6}$. Este discurso expressa a importância do relacionamento aberto e a valorização dos profissionais, porém isso não se percebe ainda no serviço público, uma vez que, nas políticas vigentes dos programas de saúde e nas quais estão inseridas as enfermeiras que desenvolvem a assistência pré-natal, o que prevalece é o uso das pessoas a serviço da produção, e não para proporcionar satisfação no trabalho como pessoa humana.

A competência social então é definida como a capacidade de relacionamento humano com pessoas e grupos, bem como de trabalhos em equipe 9 . Nesse sentido, a enfermeira, no desenvolvimento de suas atividades junto às gestantes no prénatal, tem um campo propício para desenvolver esta competência e exercitar os princípios de cidadania. Vejamos as expressões das depoentes:

[...] eu tenho compromisso com meu trabalho, procuro atender a clientela da melhor forma possível; isso éo que eu posso contribuir para amenizar todas as deficiências que existem na rede básica de saúde. Creio que hoje o meu compromisso é com a clientela [...] (Ágata Verde)

\section{[...] como enfermeira, eu procuro fazer o melhor na} minha assistência junto às gestantes e com a clientela em geral, mas é muito pouco, elas precisam de muito mais, não é só orientar [...] (Ametista)

Na análise das enfermeiras, identificamos de forma clara a percepção sobre o desempenho como competência social, apesar de que estas depoentes não dimensionam a importância de seu papel social junto às gestantes na assistência pré-natal; este papel social ainda é de forma velada. Percebemos, também, que as enfermeiras, na visão da clientela, são identificadas, dentre os demais profissionais, como aquelas que proporcionam mais escuta, mesmo diante da realidade de sobrecarga nas atividades diárias.

Contrapondo esta análise, na maioria das vezes, é visível para as enfermeiras envolvidas na assistência pré-natal a necessidade de reconhecimento e motivação por parte da instituição de saúde, identificando uma preocupação maior voltada para a supervalorização da dimensão tecnológica nas práticas de saúde ${ }^{(13 ; 14)}$

Nos relatos abaixo procuramos identificar os depoimentos que corroboram o pensamento descrito:

[...] no serviço público não temos motivação nenhuma, eu me esforço para atender bem a clientela, elas não merecem ser atendidas de forma grosseira, isso eu não faço [...] (Marcassita). 
[...] os profissionais não recebem nenhum tipo de reconhecimento, nem de ofertas no treinamento voltado para a assistência pré-natal. Temos um serviço pré-natal fragilizado no nível de SUS [...] (Diamante).

[...] não tenho motivação nenhuma, sou cobrada para executar tarefas, o que importa é a quantidade, não importa quantas gestantes temos que atender [...] (Esmeralda).

Os depoimentos acima demonstram que as enfermeiras têm visibilidade quanto à necessidade de investimento institucional para aprimoramento da qualificação profissional. Atribuem de forma clara que a clientela merece ser bem assistida e os profissionais precisam ser reconhecidos e qualificados. Reforçam, também, a cultura de avaliar a qualidade dos serviços por quantidade de atendimentos, número de consultas, número de exames solicitados, entre outros. A motivação e 0 reconhecimento profissional devem ser, na percepção delas, uma preocupação para que a enfermeira apresente uma assistência com qualidade pessoal e profissional.

Concordamos com Leitã $0^{15}$ quando defende a tese de que avaliar o desempenho da enfermeira não está ligado somente ao estímulo salarial, mas ao desenvolvimento individual e organizacional, o que possibilita a mensuração do desempenho. Vejamos nos relatos a seguir:

\section{[...] É executar as suas funções com competência} de acordo com sua área de atuação [...] (Rubi).

[...] Éo desenvolvimento das atividades específicas de cada profissional no sentido de alcançar determinado objetivo ou meta, podendo ser avaliado de forma satisfatória ou insatisfatória [...] (Ágata Branca).

\section{[...] É como o profissional desenvolve suas atividades no dia-a-dia, demonstrando competência e habilidade para a função que ocupa. Este desempenho depende do indivíduo e da instituição em que trabalha [...] (Rodocrosita).}

Contrapondo o pensamento de Leitão ${ }^{15}$, as enfermeiras, apesar de considerarem seus salários defasados, o que torna necessário mais de um emprego, reconhecem que o profissional deve demonstrar competência no desenvolvimento de suas atividades e, portanto, estabelecer metas no sentido de avaliar seu próprio desempenho, porém ressaltam que depende muito do apoio institucional.

\section{Categoria 2 - 0 COMPROMISSO PROFISSIONAL E SOCIAL DAS ENFERMEIRAS NA ASSISTÊNCIA PRÉ- NATAL}

Compartilhamos o conceito de competência social de Deluiz", quando refere que o "saber-ser" deve articular o saberfazer, saber-conviver e o saber-aprender. Dessa forma, compreendemos que as enfermeiras, no desenvolvimento da assistência pré-natal, procuram estabelecer com a clientela 0 exercício dos saberes, ainda que de forma velada.

Podemos afirmar que esse exercício do saber-ser, saberfazer, saber-conviver, representa comprometimento e resulta em compromisso profissional. Com esse entendimento, as enfermeiras que desenvolvem atividades na assistência prénatal, têm comprometimento e compromisso com a saúde da clientela, como direito individual e coletivo, reconhecendo, dessa forma, a saúde como direito às condições dignas de vida e trabalho:

[...] Eu considero um grande desafio atuar na rede básica de saúde, pelas dificuldades e limitações no trabalho que enfrento e com a crise do sistema de saúde atual. Porém eu procuro atender a clientela no melhor que posso [...] (Malaquita).

\section{[...] Eu procuro ter um bom relacionamento com as gestantes e tento superar as dificuldades que existem no contexto da assistência precária do sistema único de saúde [..] (Berilo)}

As questões ligadas à competência social das enfermeiras, reveladas nos depoimentos, nos remetem a estudos que defendem uma nova filosofia administrativa, considerando a importância das pessoas na sua totalidade. No entanto, para a organização caminhar nessa perspectiva é preciso trabalhar com forte ênfase em benefício do grupo social. Com esse pensamento, Kurcgant ${ }^{16}$ assinala que a estratégia administrativa deveria promover o reconhecimento do valor de cada pessoa, além de buscar formas especiais para promover a satisfação dos profissionais.

[...] Eu fico preocupada quando falta material para exame preventivo, exame de laboratório, medicação básica da farmácia; tudo isso é horrivel para nossa clientela que é muito carente e procura a unidade para receber ajuda e, quando recebe, não tem... material. Então eu procuro proporcionar às gestantes a melhor atenção possível para elas se sentirem acolhidas, mas eu sei que na maioria dos serviços públicos a situação dos programas é de total abandono [...] (Topázio).

[.... É o compromisso com o trabalho, realizar atividades com segurança, responsabilidade, 
respeitando a clientela. Fazer o melhor de seu trabalho, ter satisfação em realizar o que é de sua competência [...] (Esmeralda).

[...] Eu me sinto segura no que realizo junto à gestante e insatisfeita pelos recursos materiais insuficientes e um sistema de saúde em precárias condições de atender a clientela com dignidade [...] (Opala).

Reafirmamos o pensamento das enfermeiras no sentido de que devem atuar de forma a garantir a integralidade da assistência, esta entendida como o conjunto articulado e contínuo das ações e serviços preventivos e curativos, individuais e coletivos, exigidos para cada caso em todos os níveis de complexidade, atendendo, assim, o que estabelece a política atual de atenção integral à saúde materna ${ }^{12}$

Na visão da competência social, o processo sócio-cultural e histórico deve ser desenvolvido como prática humanística por excelência. Para que isso ocorra, é necessário que a assistência pré-natal na rede municipal de saúde requeira conhecimentos, técnicas e uma prática de serviços baseada em valores. Como refere Macedo ${ }^{17}$, estes valores são considerados bens supremos do ser humano dotado de direitos e responsabilidades; garantem a participação e a equidade no acesso aos bens e serviços que produzam saúde.

Neste sentido, é importante resgatar a ética na produção social da saúde, como a linguagem dos princípios, a linguagem da virtude. Segundo Kurcgant ${ }^{16}$, a primeira está relacionada aos quadros clínicos, que têm sustentação nas leis e códigos, e a segunda é aplicada na atenção básica e diz respeito ao coletivo, às condições e situações de vida das pessoas na sociedade e do meio onde trabalham e vivem a cidadania.

Acreditamos que a ética como competência da enfermeira deve ser construída na prática da enfermagem em todos os âmbitos, seja na gerência de serviços, na assistência à clientela, na família e comunidade, seja no manejo de informações e dados. Nesse contexto, as enfermeiras buscam na ética os valores e princípios para sua atuação na assistência pré-natal, afirmando:

[...] É o compromisso com o trabalho, realizar atividades com segurança, responsabilidade, respeitando a clientela [...] (Esmeralda).

[...] Exercer a profissão com qualidade, habilidade, segurança, compromisso, é aplicar na prática tudo o que você aprendeu em relação a sua profissão. (Rodonita).

[...] Realizar meu trabalho de forma consciente, comprometida com a clientela [...] (Safira Azul).
[...] É o cumprimento de seu dever, compromisso profissional e institucional, acima de tudo ser ético - valorizar as queixas, saber ouvir e criar um clima de confiança com sua clientela, para poder dar solução e/ou encaminhamento para os problemas de saúde [...] (Ágata Verde).

A assistência pré-natal, como espaço de atenção básica, apresenta uma interface importante com a população atendida pelo sistema de saúde como um todo, permitindo evidenciar as condições de atendimento à clientela. Nesse espaço, o compromisso social da enfermeira compreende a responsabilização pelos direitos de cidadania da população e a prestação de serviços às gestantes com acolhimento, qualidade e resolubilidade.

Cabe, portanto, às enfermeiras, entre outras atividades diretamente relacionadas à sua atuação com as gestantes, realizar o exercício de liderança junto a equipe profissional, assim como o gerenciamento dos recursos - físicos, materiais, humanos, financeiros, políticos e de informação - para a prestação da assistência de enfermagem.

Desta forma, torna-se necessário que sejam exigidos conhecimento (conheça o que faz), habilidades (faça corretamente) e atitudes adequadas para o desempenho do seu papel profissional, objetivando resultados positivos. Nesta perspectiva, o ensino baseado em competências vem sendo apontado como uma das estratégias para estas mudanças, e tendo sido indicado nas Diretrizes Curriculares para os Cursos de Graduação em Enfermagem ${ }^{18}$.

É pertinente ressaltar que o compromisso implica a construção de uma consciência sanitária crítica às formas injustas de distribuição dos serviços de saúde, à crescente dependência tecnológica, à mercantilização da saúde, o que pode ser assegurado com uma prática comprometida com a solução de problemas de saúde coletiva, que seja a expressão social, levando em consideração a sociedade na qual se encontra inserida a enfermeira.

Nesse sentido, o compromisso social, como uma atitude manifestada pelas enfermeiras em sua conduta diante das gestantes, reflete a necessidade da busca de uma consciência crítica da realidade que enfrentam na assistência pré-natal desenvolvida nas Unidades Municipais de Saúde e, principalmente, o empreendimento profissional na atuação cotidiana e o interesse em superar as dificuldades que são reflexas da crise no serviço de saúde pública.

\section{CONSIDERAÇÕES FINAIS}

Esta análise possibilitou uma abordagem qualitativa do desempenho profissional das enfermeiras na assistência prénatal, no sentido de descrever e analisar este desempenho e a percepção delas sobre a competência social para desenvolver a melhoria da qualidade da assistência prestada. Visualizar as possibilidades de desenvolver a assistência de forma 
competente é, portanto, um grande desafio para as enfermeiras que atuam nas Unidades Municipais de Saúde.

Existe, por parte das depoentes, a preocupação em atender à clientela, porém, colocam em evidência as dificuldades de estrutura física em que se encontram as Unidades Municipais de Saúde e ressaltam, principalmente, a preocupação com o cumprimento de metas e a produção de serviços. Foram considerados fatores importantes pelas depoentes a motivação e o reconhecimento institucional, abordados como determinantes de incentivo para o crescimento pessoal e profissional destas profissionais.

Dessa forma, evidenciamos que a situação apresentada interfere no desempenho profissional. Pois, o que se deve ter em foco na prestação de serviços é que a visão antecedente ao processo é, em parte, limitada, porque, na maioria das vezes, o serviço é produzido e consumido simultaneamente. As enfermeiras apontaram como ponto de referência para a melhoria do desempenho profissional a necessidade de investimento no conhecimento, promoção de cursos de atualização, treinamento e pós-graduação em enfermagem obstétrica.

Um fator importante verificado nesta pesquisa aponta que não basta que os profissionais sejam competentes, é preciso que estejam inseridos em uma instituição que vise promover ações que vinculem o desenvolvimento profissional ao desempenho e a competência. Na percepção das depoentes, torna-se necessário redirecionar as atividades das enfermeiras, e neste processo a implantação da sistematização da assistência de enfermagem na rede municipal de saúde surge como estratégia para aplicar o diagnóstico de enfermagem e realimentar as atividades a serem desenvolvidas pela enfermeira na assistência pré-natal.

Valorizar os profissionais de saúde e ampliar a capacidade de integrá-los ao ambiente de trabalho continua sendo, portanto, um grande desafio. A esse respeito, ainda persiste um dos pilares do Modelo de Qualidade em que prevalece a satisfação dos clientes externos e internos, de modo a satisfazer ou superar as suas expectativas.

\section{Referências}

1. Motta PR. Transformação organizacional, teoria e a prática de inovar. Rio de Janeiro(RJ): Qualitymark; 2004.

2. Witt RR. Competências da enfermeira na atenção básica: contribuição à construção das funções essenciais de saúde pública. [tese de doutorado]. Ribeirão Preto (SP): Escola de Enfermagem/ USP; 2005.

3. Deluiz N. Qualificação, competências e certificação: visão do mundo do trabalho. Formação, Brasília (DF) 2001;1(3): 5-15.

4. Cunha ICKO, Neto FRGX. Competências gerenciais de enfermeiras: em novo velho desafio? Texto \& Contexto Enferm 2006 jul/set; 15(3): 479-82.

5. Oliveira HC. 0 jogo da malha: recursos humanos e conectividade. Rio de Janeiro (RJ): Qualitymark; 2004.
6. Motta PR. Desempenho em equipes de saúde. Rio de Janeiro(RJ): Ed FGV; 2001.

7. Moller C. 0 lado humano da qualidade. Tradução de Nivaldo Montingelli Junior. $12^{\mathrm{a}}$ ed. São Paulo(SP): Pioneira; 1992.

8. Minayo MCS. 0 desafio do conhecimento: pesquisa qualitativa em saúde. $7^{\text {a }}$ ed. São Paulo(SP)/Rio de Janeiro (RJ): Hucitec/ABRASCO; 2000.

9. Chiavenato I. Gestão de pessoas: e o novo papel dos recursos humanos nas organizações. Rio de Janeiro(RJ): Elsevier; 2004.

10. Bardin L. Análise de conteúdo. Lisboa(P0): Ed 70; 1979

11. Martins CA, Pereira SVM. Qualidade da assistência obstétrica e perinatal em hospital amigo da criança: experiência de uma maternidade. Esc Anna Nery Rev Enferm 2002; 6(3): 451-53.

12. Ministério da Saúde (BR). Secretaria de Atenção à Saúde. Departamento de Ações Programáticas Estratégicas. Política Nacional de Atenção Integral à Saúde da Mulher: plano de ação 2004-2007 Brasília(DF); 2004.

13. Cunha KC, coordenadora. Gerenciamento na enfermagem: novas práticas e competências. São Paulo(SP): Martinari; 2005.

14. Rabaglio MO. Ferramentas de avaliação desempenho com foco em competências. Rio de Janeiro(RJ): Qualitymark; 2004.

15. Leitão RER. A qualidade nos serviços de enfermagem segundo percepção de enfermeiras que vivenciam essa prática. [tese de doutorado] São Paulo (SP): Escola de Enfermagem/USP; 2002.

16. Kurcgant P. Administração em enfermagem. São Paulo(SP): EPU; 2005.

17. Macedo CG. La salud publica en las Américas: documento conceptual y operacional. In: Organización Panamericana de la Salud-OPS. Educación en salud publica: nuevaes perpectiva para las Américas. Washington(USA); 2001. p. 1-16.

18. Conselho Nacional de Educação (BR). Câmara de Educação Superior. Resolução CNE/CES n 3, de 09 de novembro de 2001. Dispõe sobre as diretrizes curriculares para os cursos de graduação em enfermagem. Diário Oficial da Republica do Brasil, 9 nov. 2001. Seção 1: p.37. 